$a$

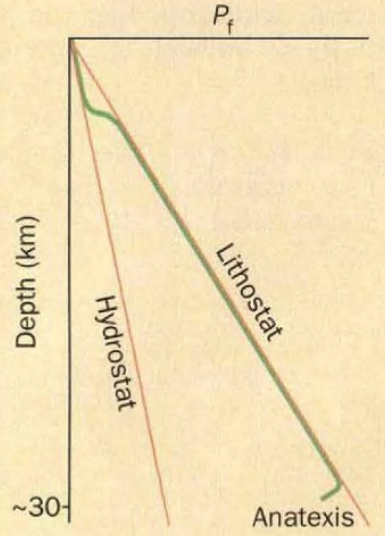

$P_{f}$

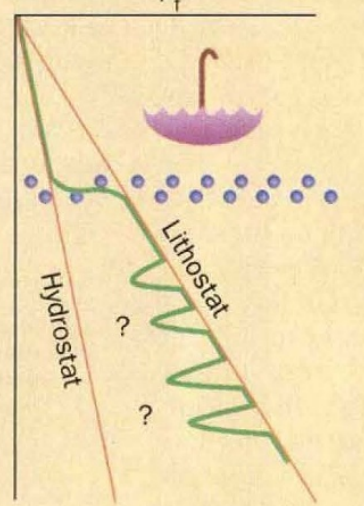

$P_{f}$

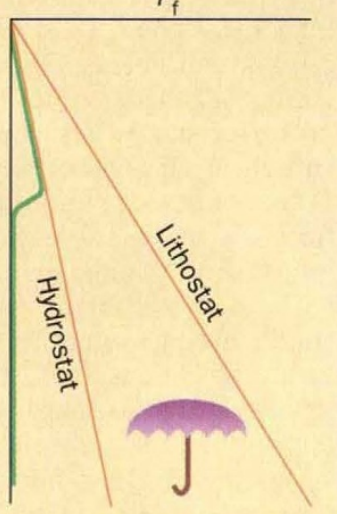

Alternative models for crustal fluids illustrated by schematic plots of fluid pressure $\left(P_{f}\right)$ as a function of depth. a, Condition during burial and progressive metamorphism of sediment to the onset of melting (anatexis). $b, c$, Alternatives for stable continental crust. In $b$ there is a continuous fluid phase through all or part of the ductile lower crust, prevented from moving up by a zone of immiscible fluids (see page 238 of this issue) ${ }^{1}$. In $c$ the lower crust has fluid in isolated inclusions only, and is a potential sink for water from above. The umbrellas emphasize the alternative flows that the models imply.

pressured fluid. Nevertheless, the simplest explanation of increased conductivity in the deep crust is the presence of a continous, lithostatically pressured, water-rich fluid.

A physical difficulty with this model is that the crust is probably too permeable to keep overpressured fluids bottled up at depth over geological timespans once metamorphism has ceased to replenish them. Bailey's contribution has been to show how an impermeable barrier might develop in the mid-crust, above the brittle-ductile transition, through the interference of migrating immiscible water and carbon dioxide fluids. He assumes that the fluid rising out of the deeper crust is dominated by (relatively dense) carbon dioxide which initially contains dissolved water, and as the water exsolves it plugs the conduits to $\mathrm{CO}_{2}$ migration. This is a physically feasible mechanism to contain some types of deep fluid at high pressure. Perhaps geologists and petrologists have failed to recognize former deep 'water sills' in rocks exhumed to the surface?

The evidence for a dry deep crust is from rocks such as granulites ${ }^{6}$, which formed at high temperatures and are important constituents of the lower crust today. The anhydrous minerals in these rocks react very rapidly with water under the conditions that prevail in stable lower crust, and such reactions would consume all available water, possibly leaving isolated traces of salts and $\mathrm{CO}_{2}$ (refs 6,7). Because fresh high-temperature minerals have survived in abundance to the surface, petrologists argue against the persistence of a continous aqueous (conducting) fluid phase at depth. Where granulites have undergone retrograde hydration, this generally occurred at low temperatures along joints and fractures, after the rocks had been uplifted through the brittleductile transition.

Thus the alternative to the model espoused by Bailey is that deep stable crust does not contain interconnected fluid in fluid-rich layers; any fluid is in isolated pores or inclusions, perhaps transiently migrating down along faults and shear zones ${ }^{8,9}$. In this case, deep seismic reflectors are due to lithological contacts or mylonite zones, and the electrical conductivity may be due to factors other than water: conductive minerals, graphite films on grain boundaries and enhanced intrinsic conductivity of mafic rocks have all been cited. Fluid immiscibility helps to overcome one theoretical obstacle to the hypothesis of deep crustal water, the need for an aquitard, but it does not explain the petrological and geochemical evidence which calls for dry conditions in stable lower crust.

Bruce W. D. Yardley, of the Department of Earth Sciences, University of Leeds, Leeds LS2 9JT, UK, is currently at the Department of Geology and Geophysics, University of Wisconsin, Madison, Wisconsin 53706 , USA. John W. Valley is in the Department of Geology and Geophysics, University of Wisconsin, Madison, Wisconsin 53706 , USA.

1. Bailey. R. C. Nature 371. 238-240 (1994)

2. Bonham, L. C. Am. Assoc. Petrol. Geol. Buil. 64, 549-567 (1980)

3. Green, A. G. et al. Geophys. J. 89, 685-690(1987)

4. Rumble. D. Eur. J. Mineral. 1, 731-737 (1989)

5. Boden, A. \& Eriksson, K. G. Deep Drilling in Crystalline Bedrock, Vol 1 (Springer, Berlin, 1988)

Valley. J. W. Bohlen. S. R., Essene. E. J. \& Lamb, W. Valley. J. W. . Bohlen. S. R., Ess
J. Petrol. 31, 555-596 (1990).

7. Morrison, J. \& Valley, J.W. J. Geol 99. 559-570 (1991)

8. Banks. D. A. Davies, G. R., Yardley, B. W. D. McCraig. A M. \& Grant, N. T. Geochim cosmochim. Acta 55, 1021 $1030(1991)$

9. Jenkin, G. R. T., Craw. D. \& Fallick. A. E. J. metamorph Geol, 12, 429-444 (1994).

\section{Corn circles}

A TREE grows directly against the forces upon it. Thus the trunk climbs upwards against gravity, and the branches grow prestressed against gravitational sagging. Some paim trees show a spiral structure, which tends to be left-handed north of the Equator, and right-handed south of it. Atmospheric eddies show this same pattern of handedness, derived from the Earth's rotation. So Daedalus reckons that these trees are reacting. against the slight but persistent rotation applied to them by eddies in the local wind.

Daedalus hopes to test this notion by transplanting palms and other trees repeatedly between Britain and Australia, to see what they do. But he is also applying the torques directly. DREADCO foresters with ropes and windlasses are twisting the tops of selected trees, putting the whole trunk under a permanent torque. A tree grows by laying down a new outer layer of living wood over the existing core every year. Under torque, it should lay down a growing layer whose grain would not be vertical, but would climb helically upwards round the tree. Next year the foresters will reverse the torque: the next outer layer will form a reversed helix. By annually reversing a torque of the right value, successive helical layers of grain could be 'braided' at about $90^{\circ}$. This, of course, is the secret of plywood, whose successive plies are cross-grained in just this way. Daedalus has invented natural plywood.

Grain braiding should work on the branches as well as the trunk of the tree. DREADCO's natural plywood will be wonderfully strong in all directions, with no weak 'end grain'. When the humidity changes, it will swell and shrink evenly, without warping. Carpenters, yachtsmen and house builders will specify it for all their best work.

Agriculture could benefit too. Wheat, maize and rice, those vital cereals, have fragile stalks, easily broken by rough wind and weather. A braided helical fibre structure should strengthen them wonderfully. No farmer could apply individual reversing torques to millions of plants; but he could surround his field with vertical-axis wind turbines.

Clockwise turbines would induce an anticlockwise eddy in the field. Reverse them, and they would induce a clockwise eddy instead. Repeat the process at intervals, and the growing crop would be strengthened by the helical braiding of the fibres of its stalks. It can now be revealed that the enigmatic corn circles in some British fields are the result of over-enthusiastic DREADCO pilot experiments.

David Jones 